\title{
OLHARES E CONCEITO DE CLÍNICA AMPLIADA: ATENDIMENTO CLÍNICO EM UMA ASSOCIAÇÃO DE PAIS E AMIGOS DOS EXCEPCIONAIS (APAE)
}

\section{Extended clinic look and concept: clinical care in an exceptional parents and friends association (EPFA)}

Clarissa de Moraes Guth - Centro Universitário Ritter dos Reis/Brasil

RESUMO: O presente artigo trata-se de uma revisão bibliográfica sobre o conceito de clínica ampliada. O artigo busca relacionar o conceito de clínica ampliada com o fazer clínico realizado em uma Associação de Pais e Amigos dos Excepcionais (APAE) do município de Cachoeirinha-RS. O objetivo principal do artigo é discutir essa relação/aproximidade do fazer clínico dessa entidade de assistência social com conceito de clínica ampliada. Assim ficou concluído que, há relação entre o fazer clínico da instituição com o conceito de clínica ampliada, uma vez que, há preocupação maior com o sujeito e sua subjetividade e integralidade do que seu diagnóstico.

Palavras-chave: Clínica Ampliada, Equipe Interdisciplinar, Saúde Mental, Estágio Clínico, Psicanálise, Atenção Psicossocial.

ABSTRACT: resumo no idioma inglês.

Keywords: as mesmas palavras-chave, mas no idioma inglês.

\section{INTRODUÇÃO}

Ao se buscar por modos de se vivenciar um fazer clínico que englobe o todo, o complexo jogo ao qual fazem parte os profissionais inseridos na clínica do desenvolvimento infantil, observa-se que se faz de extrema importância a interconexão com diferentes áreas e um olhar ampliado.

Quando olhamos para um sujeito em sua singularidade, acabamos por certificarmos a este de que pode se constituir como um indivíduo completo e tomado por um desejo que é só seu e que é único. Para que isso realmente aconteça, é relevante um olhar holístico, uma ética que trabalhe com respeitar dos sujeitos, em uma linha horizontal, ou seja, simétrica e uma atitude profissional que se faça aberta a trocas que, possibilitarão no futuro, o vir a ser desses sujeitos. E é com base neste pensar que o

Educação, Psicologia e Interfaces, Volume 3, Número 3, p. 69-84, Maio/Agosto, 2019.

ISSN: 2594-5343. DOI: 
presente artigo, se propõe a discutir a relação do conceito de clínica ampliada com o trabalho clínicoconduzido em uma Associação de Pais e Amigos dos Excepcionais (APAE).

A proposta de clínica ampliada parte do entendimento do significado de adoecer, este significado seria o tratar a doença no contexto em que está inserida, no próprio contexto de vida dos sujeitos acometidos por ela. Sua maior finalidade, não é a de somente investigar o sujeito, até encontrar a causa do que sofre e classificá-lo, procurando diagnosticar a partir dos sintomas que o afligem, porém é enxergar e procurar tratar os sujeitos em sua total integralidade. "Trata-se de uma proposta de diálogo entre a psicologia clínica e a social, que busca enfatizar a dimensão comunitária do ser humano, e que amplia a atuação da psicologia nos domínios da saúde" (CAMPOS; DOLTRO, 2015, p. 60).

Ao ampliarmos nosso olhar para áreas que se conectam ou pelomenos, deveriam se conectar com o contexto de vida e de saúde dos sujeitos assistidos, é que podemos dar vida ao trabalho clínico. Dando enfoque maior ao que se deve sobressair, no caso da clínica ampliada, são as singularidades dos sujeitos, sem que os fragmentemos em partes ou utilizemos seu diagnóstico como sendo o seu nome. E é neste contexto contemporâneo que podemos observar o crescimento de clínicas que apostam em atendimentos em equipe, com enfoque interdisciplinar. Este enfoque, segundo a maioria dos que trabalham com saúde, principalmente a área da saúde mental, concordam que esta modalidade é a melhor em termos de compreensão dos sujeitos e também uma forma de adquirir a riqueza de conhecimentos que somente a prática os proporciona. Em termos de experiência de como olhar de forma integrada aos indivíduos, entrelaçando e compartilhando metas e dividindo espaços que não são de conhecimento de suas expertises, pode setencionar ou criar novos espaços e soluções para um mesmo problema que se aponta.

Este campo de atuação tem demandado novas formas de compreensão e modelos de atuação por parte dos profissionais da área, em especial na clínica, de forma a responder com mais efetividade às demandas da sociedade, emergindo assim o conceito de clínica ampliada (CAMPOS; DALTRO, 2015, p. 60).

O fazer de uma clínica ampliada faz romper as barreiras que parecem segurar as atuações dos profissionais, romper com essas barreiras, é também acabar com os limites impostos pela clínica tradicional, a qual desde muito aprendemos a reproduzir. Por tanto

Educação, Psicologia e Interfaces, Volume 3, Número 2, p. 69-84, Maio/Agosto, 2019. 
Olhares e conceito de clínica ampliada: atendimento clínico em uma Associação de Pais e Amigos dos Excepcionais (APAE)

é enxergar os sujeitos como sujeitos e saber que suas dificuldades moldam aspectos de seu existir particular e também do seu modo de se comunicar com o outro, este outro que nem sempre o acolhe por lhe faltar o manejo necessário para lidar com suas diferenças. Na clínica psicológica ou no atendimento clínico em psicologia, buscamos pela escuta sensível e ativa dos sujeitos e a observação, que deve se dar de forma original, de certos aspectos do social que acabam por repercutir na vida desses sujeitos. Quando buscamos por isso, estamos tencionando ou acionando redes e ações sociais a olharem para o mesmo indivíduo, assim construímos um laço, a partir do diálogo com outros espaços, fazendo com que se comuniquem os sujeitos, seu mundo e sua cultura (CAMPOS; DOLTRO, 2015). Por acionar dispositivos que olhem para o mesmo indivíduo que estamos olhando como profissionais, podemos proporcionar um bem estar e de forma positiva o inserir em seu espaço por direito e ajudando o indivíduo se produzir em seu coletivo

A clínica em psicologia em seu início e até pouco anos, se dava de forma individualista e elitista, com horário e setting definidos, ou seja, bem aos moldes tradicionais (CAMPOS; DALTRO, 2015). De alguns anos até o momento presente, essa clínica está se propondo a um modo diferente de pensar seu fazer clínico, se ocupando de pensar sobre questões sociais e de cidadania.

Está se ajustando ao social, não estando sua participação restrita apenas a discutir assuntos em termos teóricos, mas propondo ações e fazendo surtir efeitos na comunidade em seu entorno. Este tipo de pensar e de atuar em atendimento clínico é recente, ainda em construção, este paradigma busca novas formas de reorganização dos serviços de saúde (CAMPOS; DALTRO, 2015). A clínica ampliada, como o próprio nome diz, vem trazer uma forma de práxi diferenciada das demais, visando enxergar os sujeitos como sujeitos e junto deles o seu contexto de vida, ampliando olhares, relacionando clínica e comunidade. Este modelo de clínica visa tratar dos riscos de vulnerabilidade dos sujeitos, sendo que estão incluídos nesse olhar, a educação em saúde e o apoio psicossocial. Nisto a clínica ampliada se propõem a convocar os sujeitos em sua autonomia, à participação ativa, para a melhoria das condições sociais, ou seja, chamar este sujeito a implicar-se em relação as suas condições presentes (CAMPOS; DALTRO, 2015). Segundo os autores citados por Lopes et al (2016, p. 78):

A clínica ampliada foi proposta inicialmente por Campos (1997) e pode-se ser entendida como um fazer clínico que ultrapasse a noção

Educação, Psicologia e Interfaces, Volume 3, Número 3, p. 69-84, Maio/Agosto, 2019. ISSN: 2594-5343. DOI: 
hegemônica que separa o sujeito da doença que este apresenta. Ela compreende o sujeito através de um olhar integral, holístico, pois entende que as pessoas não se limitam às expressões das doenças de que são portadoras.

Segundo Cunha (2010), este tipo de fazer clínico deve se ocupar de respeitar a singularidade dos sujeitos assistidos, mas não abrindo mão da atenção às doenças, possibilidades de se fechar um diagnóstico, se necessário, e de se realizar intervenções se for o caso (LOPES et al. 2016). Compreende-se que em clínica ampliada o sujeito deve ser entendido sob seu contexto familiar, sob o contexto de suas relações da escola, do trabalho e também sob tantos outros ambientes pelos quais circula. Descentraliza a doença do sujeito, pois aceita essa como mais um acontecimento na vida dele e que está conectado com outras dimensões de sua vida como a familiar, a social e a por fim a cultural. Com isso, Lopes et al (2016) coloca que:

Diante desses pressupostos, é importante destacar o reconhecimento dos limites de cada campo do saber. Esses pressupostos ecoam em uma prática multi/interdisciplinar das políticas públicas de saúde. A Clínica Ampliada pressupõe um deslocamento da hegemonia do saber médico em detrimento dos outros saberes para uma abordagem do Sujeito a partir de diversas disciplinas, tais como Fisioterapia, Psicologia, Terapia Ocupacional e Farmácia, dentre outras (LOPES et al. 2016, p. 79).

Isso se torna importante, porque retira a supremacia de apenas uma área que se ocupa de diversas situações, como por exemplo, a médica e coloca ou desloca a responsabilidade e o querer fazer, para outras áreas que juntas pensarão sobre o problema/dificuldade. $\mathrm{E}$ é por este motivo que o trabalho interdisciplinar/multidisciplianar, se relaciona diretamente com o conceito de clínica ampliada, pois enxergando o sujeito como portador de seu desejo e não somente de sua patologia, é que por meio de trocas constantes, melhora a atuação em atendimento clínico. Todo esse conjunto citado também compartilha aspectos da chamada atenção psicossocial, uma vez que está em constante interação com os espaços que sujeito circula e com o seu contexto. Benevides et al (2010, p.128) afirmam que:

A atenção psicossocial direciona suas ações para a construção da cidadania, da autoestima e da interação do indivíduo com a sociedade. Nesta realidade, a reprodução social do sujeito em sofrimento psíquico perpassa a prática clínica e constitui um processo complexo. Assim, a prática clínica exercida na rede de atendimento requer instrumentos e estratégias para a efetivação de ações resolutivas.

Educação, Psicologia e Interfaces, Volume 3, Número 2, p. 69-84, Maio/Agosto, 2019.

ISSN: 2594-5343. DOI: 
Olhares e conceito de clínica ampliada: atendimento clínico em uma Associação de Pais e Amigos dos Excepcionais (APAE)

Segundo Amarante (2010) coloca que é preciso reinventar a clínica, mais precisamente renovar o fazer clínico e isso começa pelo atendimento clínico que se faz. Segundo ele, tem que haver a reconstrução da prática em clínica a partir da subjetividade, colocando a própria, como processo de construção de possibilidades. É preciso se ocupar do sofrimento dos sujeitos de verdade, buscando se responsabilizar por aqueles que sofrem e também se ocupar dos processos de cidadania dos mesmos de forma ética. Necessitamos de uma clínica que não se apresente como estratégia de normalização e de disciplina e o principal, precisamos de profissionais que acreditem no que fazem (AMARANTES, 2010).

Quando afirmou isto, estava a debater sobre a psicanálise, ele diz que é preciso que os profissionais acreditem no que fazem, acreditem que com a psicanálise é possível mudança. Ele colocou desta forma, porque o que necessitamos é formar complexidade para tratar de problemas que em sua maioria são complexos. Não precisamosinventar uma disciplina específica que se ocupe do que ainda parece não haver solução, precisamos formar soluções com as ferramentas que temos em mãos. A cartilha publicada pelo SUS no ano de 2010 descreve sobre o porquêprecisamos de uma clínica ampliada em nosso sistema de saúde. Ela trás como um dos motivos a articulação e a inclusão dos diferentes saberes, pois nem todos isoladamente conseguirão resolver todos os tipos de problemas que chegam até a clínica (BRASIL, 2010).

Isso se afirma quando esclarece que "a Clínica Ampliada reconhece que, em um dado momento e situação singular, pode existir uma predominância, uma escolha, ou a emergência de um enfoque ou de um tema, sem que isso signifique a negação de outros enfoques e possibilidades de ação" (BRASIL, 2010, p. 11).

Já o outro motivo descrito diz respeito a questão da autonomia do usuário em relação a sua participação ativa em seu processo/projeto terapêutico. Pois há a necessidade de compartilhamento com os usuários dos diagnósticos e condutas em saúde e isso se faz tanto ao nível individual quanto ao nível coletivo (BRASIL, 2010). Com isso podemos certificar que o conceito de clínica ampliada abrange inúmeras possibilidades de intervenção e não se restringe apenas a um campo de atuação.

A clínica ampliada vem possibilitar uma nova prática que envolve o atendimento clínico, seja qual for a abordagem ou a modalidade deste atendimento e vem gerar espaço para a autonomia dos sujeitos. A autonomia como espaço para os sujeitos se constituírem

Educação, Psicologia e Interfaces, Volume 3, Número 3, p. 69-84, Maio/Agosto, 2019. ISSN: 2594-5343. DOI: 
como indivíduos dotados de potência, apesar de serem portadores de dificuldades desenvolvimentais. Esta modalidade de clínica abre o horizonte do fazer em saúde proporcionando a complexa interação intersetorial, interdisciplinar e acaba rompendo com o conceito de que clínica se faz em quatro paredes. Acaba por mostrar que clínica se faz e se refaz durantes os tempos e que clínica se faz onde houver sujeitos dispostos a olhar para outros sujeitos como sujeitos.

Então cabem aos profissionais da saúde, em conjunto com educadores e demais profissionais, que fazem parte da vida dos sujeitos que atendem a discussão deste fazer. Por este motivo é que o presente artigo se propõe a fazer esta relação entre clínica ampliada e o atendimento clínico, para acionar reflexões a cerca deste tema e contribuirpara a discussão sobre o fazer clínico. O artigo busca de forma qualitativa, a partir da observação e das vivências do estágio específico em uma Associação de Pais e Amigos dos Excepcionais, discutir a relação do atendimento clínico executado e o conceito de clínica ampliada.

\section{METODOLOGIA}

O presente artigo trata-se de uma revisão bibliográfica a respeito da clínica ampliada e de questões que envolvem o fazer clínico, tendo como base teórica, a psicanálise. $\mathrm{O}$ artigo busca colaborar com a literatura sobre as relações entre o conceito de clínica ampliada e a prática clínica, em uma instituição de assistência social no município de Cachoeirinha - RS. A Associação de Pais e Amigos dos Excepcionais (APAE), realiza atendimento clínico em áreas como, a Psicologia, a Fonoaudiologia, a Psicopedagogia, a Estimulação Precoce e a Fisioterapia.

A população atendida pela APAE de Cachoeirinhaé composta de crianças e adolescentes, abrangendo questões da área do desenvolvimento como deficiências múltiplas. A partir das observações do último estágio específico com ênfase em processos clínicos, também se busca relacionar acontecimentos do estágio com o desenvolvimento teórico produzido no presente artigo.

\section{AMPLIANDO OS OLHARES}

Nós indivíduos fazemos parte de algo muito maior do que simplesmente pertencer a uma comunidade, frequentar espaços como nosso bairro, rua, casa, escola, hospitais e

Educação, Psicologia e Interfaces, Volume 3, Número 2, p. 69-84, Maio/Agosto, 2019. 
Olhares e conceito de clínica ampliada: atendimento clínico em uma Associação de Pais e Amigos dos Excepcionais (APAE)

praças. Nós pertencemos a algo mais complexo chamado sociedade, somos integrados a ela, participamos como cidadãos e somos detentores de direitos universais.

Na visão da Organização Mundial da Saúde (OMS), sobre o conceito de saúde, trás que ela seria um estado de completo bem-estar físico, mental e social, onde não se limitaria apenas a ausência de enfermidades. Com isso se tem uma ampliação do que seria a saúde, pois esta passou a ser priorizada não somente pelo indivíduo, mas também pela comunidade. A saúde tornou-se um valor da comunidade e não só do indivíduo que dela necessita, o que se remete ao olhar holístico, ou seja, a atenção volta-se tanto para os sujeitos quanto para o seu espaço social. Já, por sua vez, a visão da clínica ampliada sobre os sujeitos, passa também por este olhar, é o considerar que eles, os sujeitos, vão muito além da interioridade, pois os considera sujeitos em completa interação bio-sócio-psicoespiritual, incluindo também os campos da política e da economia (CAMPOS; DOLTRO, 2015).

Por esse motivo, vemos ocorrer em nossa sociedade acontecimentos que chegam até nós e nos afetam, não ter habitação favorável ou condições essenciais, como passagem para o deslocamento ou alimentação, nos afeta. Essas condições também são as responsáveis por nossa forma de constituição como um corpo que deve possuir espaço, espaço no sentido de lugar no mundo, ser reconhecido como um sujeito dotado de desejos e de capacidades. Exatamente como Françoise Dolto nos fez reconhecer a criança como um sujeito, o autor Halmos (1989), diz que a teoria de Dolto nos forneceu, a partir da psicanálise, enxergar o lugar da criança como o lugar próprio delas, propondo ouvir o que elas dizem ao invés de falar delas (SOLER; BERNARDINO, 2012). E quando isso não nos acontece, sobressaem-se as dificuldades, não somente no indivíduo que sofrecomo os que estão entorno dele, também sofrem. Toda a família parte para uma desestruturação, algo que balança seu funcionamento rotineiro, para que a mesma consiga ter forças para se reestruturar novamente (DIAS, 2011). Porém o que vemos, na maioria das vezes, em se tratando de famílias menos abastadas, juntando com as dificuldades associadas a todas as áreas citadas, é a falta de poderem se reestruturarem sozinhas. Neste caso, não é somente o paciente que vemos em nosso cotidiano como profissionais de atendimento clínico, que precisa de ajuda, precisamos acolher também suas famílias, que mal conseguem entender o que seu parente possui, quanto muito menos, não possuem possibilidades suficientes, para sozinhos retomarem suas vidas.

Educação, Psicologia e Interfaces, Volume 3, Número 3, p. 69-84, Maio/Agosto, 2019. ISSN: 2594-5343. DOI: 
Essas dificuldades somadas a pré-disposições, principalmente quando o ambiente não lhe é favorável em termos de sustentação do corpo psíquico, é quando nos chegam ao atendimento clínico. O desenvolvimento já possui sua própria complexidade, jaz que encontramos diversos ciclos e estágios se dando de diversas formas nos sujeitos, esses momentos transitórios, ás vezes não são bem concluídos, ademais quando acompanhados de problemas de assistência social (EIZERIK; BASSOLS, 2013).

Considerar o desenvolvimento a partir do critério curso de vida impõe, por outro lado, dificuldade para distinguir o que é normal ou patológico nesse processo, já que envolve interações complexas que influenciam no ajustamento futuro do indivíduo. Um desses aspectos interacionais concerne à organização/funcionamento familiar (MARTINS, SANTOS; PILLON, 2008, s/p.).

Por isso dizemos que o ambiente influencia e a família é um dos fatores deste ambiente devendo ser de suma importância no desenvolvimento dos indivíduos. Françoise Dolto (CIFALI, 1989, p. 65), nos diz que a criança adoece do inconsciente de seus pais, "uma criança herdeira de nossas dívidas de adultos, uma criança sintomática do que permaneceu atado às gerações que a precedem" (SOLER; BERNARDINO, 2012).

A escola e outros lugares em que o sujeito frequenta também lhe moldam, também lhe sustentam e fazem parte de sua constituição, podendo deixar marcas que aparecerão no futuro, seja se referindo a um diagnóstico fechado muito cedo ou se tratando de uma medicação não necessária. Um abandono ou uma rejeição na escola, também podem causar danos, o que podemos estar relacionando com o fato deste ser que sofre ser visto, que alguém possa olhar para ele com os mesmos olhos que olham para alguém, o qual, não possui dificuldades. Na clínica do desenvolvimento aparecem diversos diagnósticos e hipóteses sobre um dado sujeito, mas parece que ninguém se ocupa para além do que é portador. Parece que ninguém consegue enxergar além da dificuldade de fala, isso quando há resquício de fala ou da questão da recusa a alimentar-se, ninguém amplia o olhar para o interesse desse sujeito que possui uma vontade específica no presente.

Ampliar o olhar para a escola, ver o que está aprendendo agora, se este sujeito se interessa pelo o que aprende agora ou do que mais gosta de fazer, ou ainda, de qual aula gosta de participar, são necessários para que os sujeitos possam se constituir. Ao invés de colocações como esta, vemos a preocupação dos pais ou dos professores com o fato de quando ele vai sentar e prestar atenção na aula, quando vai entrar na sala, já que sempre

Educação, Psicologia e Interfaces, Volume 3, Número 2, p. 69-84, Maio/Agosto, 2019. 
Olhares e conceito de clínica ampliada: atendimento clínico em uma Associação de Pais e Amigos dos Excepcionais (APAE)

faz birra para entrar na aula, quando vai aprender limites, quando vai conseguir falar algo que possamos entender, que outros vão poder entender, etc.

Enquanto a preocupação maior no momento é com a constituição do corpo, de seu lugar na família, de seu espaço na escola, de ser visto primeiramente, como um sujeito e ser chamado por seu nome, parecendo não acontecer, este indivíduo não possui desejo. Não possuir desejo, pode-se ser comparado a um viver sem propósito, um sujeito sem desejo, não é um sujeito, pois não possui vontades próprias, não passa de um corpo que precisa que lhe digam o que fazer. Na clínica do desenvolvimento, os profissionais lutam por um sujeito do desejo, lutam para que aqueles que assistem tenham vontades e sejam autores de seus comportamentos, de suas atitudes e atos.

Por isso trabalhar interdisciplinarmente e em conjunto ao olhar ampliado, possibilita reinventar o que é da ordem do desejo, possibilita olharmos por de trás da patologia do sujeito e enxergá-lo como: -“um ser que é gente como a gente e gente da gente”.É preciso haver ações para além da clínica que possam enxergar o mesmo sujeito que quem trabalha com as dificuldades do desenvolvimento enxerga, é preciso transformar espaços em espaços gregários. A educação tem seu papel e ele é refletido nas escolas, um sujeito que possui atraso em seu desenvolver ou algo que já se encontra instalado em sua constituição, também deve frequentar a escola junto a seus colegas.

Porém, o mais difícil é a forma com que se coloca a questão da inclusão nas escolas e vemos que a clínica ampliada pode ser um dos caminhos para a solução desta dificuldade. Outro ponto importante é pensar na educação como educação e não pensá-la somente em educação-escola. Conforme Mozé (2013) a educação é o que de fato vai definir a exclusão ou a inclusão de pessoas no processo social. Ela diz que a desigualdade é um dos fatores que acaba fazendo o com que o contrário de tudo nunca possa fazer moradia em nosso social, questões como segregação de países, classes e os diferentes da gente, são as que mais preocupam o rumo das coisas (MOZÉ, 2013).

A autora ainda nos trás que é a troca com a cultura que o sujeito se faz autônomo de suas vontades e fazeres e é somente com ela que se humaniza, pois o humano já nasce incluso e precisa se incluir no mundo, na cultura e no natural (MOZÉ, 2013). O indivíduo precisa do Outro para se constituir, porque é a través deste Outro que ele pode se reconhecer. Quando nos propomos a falar do sujeito com dificuldades em seu desenvolvimento é difícil não adentrar em questões importantes como a escola e a

Educação, Psicologia e Interfaces, Volume 3, Número 3, p. 69-84, Maio/Agosto, 2019. ISSN: 2594-5343. DOI: 
inclusão, pois este sujeito se beneficia mais, quando seu atendimento caminha com a atenção da escola, ou dos lugares os quais freqüenta. Tem que haver comunicação intersetorial, comunicação em rede, uma rede que tece ou vai tecendo significados para a sua constituição como um sujeito que se forma capaz.

Estes sujeitos, dos quais, o artigo se propõem a refletir na grande maioria das vezes, sofrem com o não aprender como seus colegas de classe na escola, sofrem por não acompanharem seu ritmo. E este representa apenas um dos muitos motivos do porquê de existir um olhar ampliado e uma comunicação presente entre o atendimento clínico deste sujeito com a sua escola, com o professor que lhe ensina e ensina de que forma. Alicia Fernández (2001) trás que quando abrimos espaço para escutar a singularidade do pensar dos sujeitos, o trabalho psicopedagógico torna-se fascinante.

Ela diz que a atividade do pensar nasce da intersubjetividade que é promovida pelo desejo de autonomia e nutrida pela necessidade que temos de nos entender e de que nos entendam (FERNÁNDEZ, 2001). A autora ainda questiona, o fazer dos professores quando diz que eles, ás vezes comentem um “crime", ao confundir as causas do porquê um aluno não aprende, com as causas que levam um outro aluno, também a não aprender. Ela diz que o acontecimento de não conseguir aprender, porque ás vezes se esta à margem dos outros, pode ser a mesma, mas o que não pode ser igual são as causas que levaram cada um a não aprender (FERNÁNDEZ, 2001). As causas são diferentes, pois cada um dos alunos tem sua própria subjetividade, são diferentes e as soluções para sanar estas dificuldades precisam se diferenciar também. O fracasso escolar, como a autora coloca, se dá a partir desse não considerar estas diferenças e de não se comunicar para além do que observa, ou seja, ela se coloca disposta a ouvir outras opiniões e olhares diferentes dos seus, se propõem a pensar em rede (FERNÁNDEZ, 2001).

Esta forma de se permitir a fazer trocas e a buscar quem mais enxerga este sujeito além de mim e o que pensa, este Outro que também lhe observa, é fazer clínica ampliada. Pois dessa forma, estou acompanhando este sujeito em mais de um espaço além da escola ou além do atendimento clínico, estou enxergando com olhar ampliado e me certificando de seu contexto. Assim também estou conseguindo escutá-lo profundamente, cumprindo meu papel com o que se propõem um atendimento clínico, me proponho a enxergá-lo como um ser completo, um ser bio-sócio-psico-espiritual.

\section{CLÍNICA AMPLIADA EM UMA APAE}

Educação, Psicologia e Interfaces, Volume 3, Número 2, p. 69-84, Maio/Agosto, 2019. 
Olhares e conceito de clínica ampliada: atendimento clínico em uma Associação de Pais e Amigos dos Excepcionais (APAE)

A Associação de Pais e Amigos dos Excepcionais do município de Cachoeirinha - RS é uma entidade sem fins lucrativos da área da assistência social (SOUZA; BRUM, 2016). Esta entidade realiza um trabalho diferenciado que procura promover a habilitação e reabilitação dos sujeitos (SOUZA; BRUM, 2016). Ela possui uma equipe composta por profissionais que prezam pela ética em psicanálise e compõem uma equipe de atendimento clínico interdisciplinar.

Esta instituição, promovendo esta modalidade de atendimento, sendo ela interdisciplinar e conduzida por um pensar no paciente como um sujeito de vontades e autor de seus próprios atos, já está se colocando dentro do conceito de clínica ampliada. Este pensamento para além das dificuldades e do próprio diagnóstico, é o que se propõe um fazer transversal, que atravessa o convencionalismo da clínica tradicional ou o negativismo da escola e de outros espaços. Negativismo no sentido de não apostar que o sujeito é capaz à realizações, um pensar que é fechado, o qual não se consegue adentrar as crenças que já estão impostas como um fardo que o sujeito carrega consigo.

No ano de 2003, a clínica ampliada tornou-se diretriz da Política Nacional de Humanização (PNH), o que a conceituou como sendo uma ferramenta teórica e prática, possuindoa finalidade de contribuir com uma abordagem clínica em termos de adoecimento e de sofrimento.Com isso, preza-se pela singularidade do sujeito e também da complexidade do processo saúde/doença, enfrentando assim, a fragmentação do saber e das ações de saúde que buscam equilíbrio entre benefícios e danos (BRASIL, 2007).

Sendo assim, este fazer clínico não colocando o diagnóstico em primeiro lugar, não quer dizer que o ignore, porém parte-se muito mais pela busca de enxergar os sujeitos como um sujeito do desejo. Isso foi afirmado pelo autor Cunha (2010), ele coloca que a clínica ampliada deve se prestar a olhar para a singularidade dos sujeitos, mas sem abrir mão de também estar se ocupando da atenção as doenças, das possibilidades de diagnóstico e da intervenção (LOPES et al. 2016). É o que também se propõe o fazer clínico da APAE de Cachoeirinha, olhar para a singularidade dos sujeitos e seu desejo e deixar a discussão do que é normal e patológico em um segundo plano, mas sem ignorar as hipóteses diagnósticas ou o diagnóstico. E é isso o que amplia os olhares, éessa possibilidade de um olhar que contemple o todo, um olhar que seja holístico.

O trabalho de atendimento clínico da APAE do município de cachoeirinha realiza um fazer clínico que é permeado pela abordagem de orientação psicanalítica, que reúne

Educação, Psicologia e Interfaces, Volume 3, Número 3, p. 69-84, Maio/Agosto, 2019. ISSN: 2594-5343. DOI: 
o conhecimento e prática de uma equipe interdisciplinar, a partir da ética em psicanálise e ampliando olhares para outros espaços de convívio dos sujeitos que atendem. $\mathrm{O}$ atendimento clínico na instituição parte de uma prevenção desde a menor infância, em relação às dificuldades desenvolvimentais ou os chamados atrasos significativos do desenvolvimento, evitando assim, a gama de rótulos que o sujeito poderá levar consigo durante sua vida. Por tanto, o fazer clínico dessa instituição se propõe a deixar as hipóteses diagnósticas ou até mesmo o diagnóstico de lado, buscando fortalecer as potencialidades dos indivíduos, aceitando suas dificuldades como transitórias em seu percurso e acreditando no desejo dos sujeitos.

A prática clínica da entidade é conduzida por equipe interdisciplinar, o que faz com que a dificuldade do indivíduo seja olhada de diferentes enfoques, sem que tenha que passar por mais de uma modalidade de atendimento. Isso colabora para a ampliação do olhar como no conceito de clínica ampliada, o que torna-se mais um instrumento que tem se mostrado como dispositivo de resolução de aspectos abordados dentro da área da saúde. Exatamente como descrito na Cartilha do Humaniza Sus, que transcorre sobre a importância da clínica ampliada, publicada no ano de 2010 pelo Ministério da Saúde:

Trabalhar com diferentes enfoques, trabalhar em equipe, compartilharsaberes e poderes é trabalhar também com conflitos.Os instrumentos aqui propostos - Clínica Ampliada, Equipes deReferência, Projetos Terapêuticos Singulares - têm-se mostradocomo dispositivos resolutivos quer seja no âmbito da atençãocomo no âmbito da gestão de serviços e redes de saúde" (BRASIL, 2010, p. 11).

Neste contexto, o trabalho de atendimento clínico da APAE, compartilhado conceito de clínica ampliada, pois se traduz pelo mesmo significado que ela e conduz um fazer clínico que procura sempre refletir questões da saúde e das políticas publicas que circulam o seu fazer. Acaba sendo compreendido como um tipo de transformação do cenário de atenção, tanto individual quanto coletiva, permitindo ou possibilitando que outros aspectos, além do corpo orgânico, sejam também vistos, entendidos e trabalhos nos indivíduos pelos profissionais (HAFNER et al, 2010). Sempre há algo que mobiliza os profissionais da instituição em busca de conhecimento, formas de manejo diferentes, acompanham as novas linhas em atendimento presentes, etc. $\mathrm{O}$ sentido que o conhecimento proporciona a equipe é o da desacomodação, é o de buscar o olhar do outro

Educação, Psicologia e Interfaces, Volume 3, Número 2, p. 69-84, Maio/Agosto, 2019. 
Olhares e conceito de clínica ampliada: atendimento clínico em uma Associação de Pais e Amigos dos Excepcionais (APAE)

sob seu fazer clínico, é o de buscar por trocas com especificidades diversas e a constante supervisão de suas práticas.

Isso acontece, porque não se trata de desvalorizar outros olhares, aqui refletidos como outras modalidades, abordagens e enfoques diferentes, mas ao contrário, busca por integrar várias práticas, possibilitando um manejo eficaz do atendimento clínico interdisciplinar (BRASIL, 2010). Assim, tenta-se promover a discussão sobre a fragmentação do processo do fazer clínico, por isso é necessário um espaço como o de uma supervisão, com contexto favorável para a contenção de angústia e outros sentimentos provocados nos profissionais.

A entidade APAE acaba acionando diversos dispositivos como as interconsultas, as reuniões clínicas semanais, supervisão mensal dos membros da equipe e a reunião dos educadores semestral (o contato intersetorial), de forma a promover uma escuta atenta, sensível e profunda a nível holístico. Ao promover espaços, para constantes trocas entre os membros da equipe, proporciona a melhora dos atendimentos prestados. Acionando dispositivos como a reunião clínica semanal, promove a condição de se discutir aspectos importantes a respeito dos acontecimentos da instituição, por meio das pautas criadas por cada membro da equipe, se procura apontar novas ideias e soluções.

Sendo a supervisão mensal dos membros da equipe clínica interdisciplinar da instituição, um espaço para que o olhar do Outro, ou seja, um profissional não pertencente à equipe, possa estar colaborando com ampliar de olhares. Há a possibilidade de mobilizar os profissionais da equipe, como um todo, a escreverem sobre os casos que atendem, para que os mesmos sejam discutidos em supervisão. Esta, sendo também, outra forma de promover olhar ampliado sobre os sujeitos atendidos, apostando em diferentes caminhos para sanar dificuldades que possam existir entre um caso e outro, ou seja, uma assistência para pensar nos casos atendidos pela equipe da instituição.

A possibilidade do movimento da instituição a convocar educadores, orientadores e professores das escolas do município, onde ela reside, procura realizar um diálogo entre escola e saúde. Uma vez que o atendimento clínico realizado promove habilitação, reabilitação ou prevenção em termos de saúde e bem-estar, ele precisa estar constantemente, a conversar e fazer trocas com os olhares que a escola tem sobre seus alunos. Alunos que também são olhados pelo fazer clínico da instituição, estar

Educação, Psicologia e Interfaces, Volume 3, Número 3, p. 69-84, Maio/Agosto, 2019. ISSN: 2594-5343. DOI: 
promovendo espaço para que estas trocas de olhares possam acontecer, está se buscando a maneira mais adequada de se fazer inclusão.

Tudo isso, se traduz em conceito de clínica ampliada, pois quando buscamos pelo olhar do outro, abrimos espaço para diferentes formas de pensarmos os sujeitos. Sujeitos estes, que são sujeitos do desejo que precisamos buscar sempre o olhar que contemple o todo que esse indivíduo vivencia, para que possamos possibilitar a eles espaço e autonomia.Buscamos por um fazer clínico que englobe o todo, pois estamos promovendo soluções durante os atendimentos em clínica, quando estamos dispostos a ampliar nossos olhares.

\section{CONSIDERAÇÕES FINAIS}

Dessa forma é que podemos concluir que refletir sobre as diferentes práticas, que procuram atuar para prevenir ou atenuar o sofrimento dos sujeitos, é que se consegue melhorar a forma com que enxergamos e executamos o nosso fazer clínico.

Buscar por espaços para discussão desses aspectos proporciona um ampliar dos olhares de quem trabalha em clínica, criando possibilidades para que assim possamos contribuir com os processos e redes em saúde. A clínica ampliada centra-se na compreensão dos processos de saúde/doença de forma holística, compartilha a construção de diagnósticos e terapêuticas, colabora para a ampliação do objeto de trabalho, transforma os meios de trabalho e seus instrumentos e promove suporte para os profissionais (BRASIL, 2010).

Tendo em vista que a clínica ampliada tornou-se um dispositivo resolutivo no fazer clínico, ela visa também a criação de espaços para trocas entre diferentes disciplinas, além de espaço para a escuta (o acolhimento da queixa), cria-se vínculos e afetos entre profissionais e usuários e promove o diálogo intersetorial e informação (BRASIL, 2010). Neste complexo mundo do fazer clínico, colocar-se a refletir sobre a prática e dialogar sobre novos conceitos que vem aprimorar as realizações em saúde, só colabora para seu entendimento e vem fortalecer o bom manejo dos profissionais da saúde. Ao se ampliar olhares amplia-se junto a forma de se assistir os sujeitos.

O fazer clínico da Associação de Pais e Amigos dos Excepcionais do município de Cachoeirinha- RS se relaciona com o conceito de clínica ampliada, pois pensa em um sujeito para além de seu diagnóstico. É por meio de trocas interdisciplinares, movimentos

Educação, Psicologia e Interfaces, Volume 3, Número 2, p. 69-84, Maio/Agosto, 2019. 
Olhares e conceito de clínica ampliada: atendimento clínico em uma Associação de Pais e Amigos dos Excepcionais (APAE)

intersetoriais, como as reuniões de educadores, que consegue melhorar o processo de inclusão nas escolas. Possuindo um fazer clínico que é realizado através da ética em psicanálise, de uma visão holística dos processos de saúde/doença, é que podemos perceber o quanto se aproxima do conceito ético-estético e político de clínica ampliada.

Seu pensamento, permeado pela orientação psicanalítica, faz com que pensemos em um sujeito que é dotado de desejo e que podemos sempre realizar um trabalho preventivo, antes de simplesmente rotularmos os sujeitos com um diagnóstico pelo resto de suas vidas.

\section{REFERÊNCIAS BIBIOGRÁFICAS}

CAMPOS, F. A., DOLTRO, M. A clínica ampliada no enfoque da Gestalt-Terapia: Um relato e experiência em supervisão de estágio. Revista de psicologia, Diversidade e Saúde, Salvador, v. 4, n.1, p. 59-68, Novembro. 2015

LOPES, E. D., SILVA, C. F., GOMES, J. O., LIMA, A. C., ALMEIDA, H. C. M., DANTAS, J. B., GONDIM, A. P. S. Grupo terapêutico interdisciplinar: Experiência entre farmácia e psicologia. Extensão em Ação, Fortaleza, v.3, n.12, Outubro/Dezembro. 2016

FERNÁNDEZ, A. Os idiomas do aprendente. Porto Alegre: Digital Source, 2001

MOZÉ, V. A escola e os desafios contemporâneos. 2. Ed. Rio de Janeiro: Civilização Brasileira, 2013

MARTINS, M., SANTOS, M. A., PILLON, S. C. Percepções de famílias de baixa renda sobre o uso de drogas por um de seus membros. Revista Latino- am Enfermagem, v. 16, n.2, Novembro. 2008

SOLER, V. T., BERNARDINO, L. M. F. A prática psicanalítica de Françoise Dolto a partir de seus casos clínicos. Estilos clínicos, São Paulo, v.17, n.2, p.206-227, Julho/Dezembro. 2012

DIAS, M. O. Um olhar sobre a família na perspectiva sistêmica: O processo de comunicação no sistema familiar. Gestão e desenvolvimento, v. 19, p. 139-156. 2011

EIZERIK, Cláudio \& BASSOLS, Ana. O ciclo da vida humana: uma perspectiva psicodinâmica. 2. ed. Porto Alegre: Artmed, 2013.

BENEVIDES, D.S. et al. Mental healthcare through therapeutic groups in a day hospital: the healthcare workers' point of view. Interface - Comunic., Saude, Educ., v.14, n.32, p.127-38, jan./mar. 2010.

Educação, Psicologia e Interfaces, Volume 3, Número 3, p. 69-84, Maio/Agosto, 2019. ISSN: 2594-5343. DOI: 
AMARATE, P. Reforma psiquiátrica e epistemologia. Cad. Bras. Saúde Mental, v.1, n.1, Jan./Abr. 2009.

BRASIL. Ministério da Saúde. Clínica ampliada e compartilhada. 1ed. Brasília: Ministério da Saúde, p. 64. 2010.

HAFNER, M. L. M. B et al. A formação médica e a clínica ampliada: resultados de uma experiência brasileira. Ciência \& Saúde Coletiva, vol. 15, n. 1, p. 1715 - 1724, Jun./Ago. 2010.

SOUZA, A. C; BRUM, H. E. A importância da interdisciplinaridade na clínica do desenvolvimento infantil. Anais da x mostra científica do CESUCA, Cachoeirinha, n.10, Nov. 2016.

BRASIL. Ministério da Saúde. Clínica ampliada, equipe de referência e projeto terapêutico singular. 2. ed. Brasília: Ministério da Saúde, 2007.

\section{Credenciais da autora}

GUTH, Clarissa de Moraes. Centro Universitário Ritter dos Reis/Brasil. E-mail: clarissapsicologaclinica@hotmail.com

Endereço para correspondência: Clarissa de Moraes Guth. E-mail:

clarissapsicologaclinica@hotmail.com

Como citar este artigo (Formato ABNT): GUTH, Clarissa de Moraes. Olhares e conceito de clínica ampliada: atendimento clínico em uma Associação de Pais e Amigos dos Excepcionais (APAE). Educação, Psicologia e Interfaces, v. 3, n.3, p. 69-84, 2019.

Recebido: 07/06/2019.

Aceito: 20/06/2019.

Educação, Psicologia e Interfaces, Volume 3, Número 2, p. 69-84, Maio/Agosto, 2019.

ISSN: 2594-5343. DOI: 